\title{
NOS MEANDROS DA ODISSEIA DO PICAPAU AMARELO: A POÉTICA DE UM CONTADOR DE HISTÓRIAS ${ }^{1}$.
}

\author{
Fernando Teixeira Luiz
}

Universidade do Oeste Paulista - UNOESTE, Faculdade de Ciências Letras e Educação de Presidente Prudente, Presidente Prudente, SP. E-mail: fer.luiggi@hotmail.com

\section{RESUMO:}

Partindo da hipótese de que é possível flagrar nos textos de Monteiro Lobato (1882-1948) a manifestação de um particular pensamento estético, o presente artigo tem o objetivo de rastrear as declarações sobre literatura infanto-juvenil assinaladas em sua produção ao longo de mais de quarenta anos de intensa militância intelectual (1903-1948). Nesse sentido, pretende-se efetuar o levantamento, a seleção e a análise de trinta e cinco publicações literárias - abarcando o que convencionalmente se designou como "literatura geral" e "literatura infantil" - bem como cinco coletâneas de ensaios jornalísticos e três volumes de cartas editadas pela Brasiliense. Assim, os dados desse estudo serão obtidos, compilados e organizados sistematicamente com base nas orientações da crítica especializada e nas biografias que se centram no itinerário do criador de Emília. A análise do material coletado permite identificar a adesão a uma diversidade de correntes filosóficas, a subversão aos padrões estrangeiros e acentuam um fértil diálogo com inúmeros sistemas culturais, exaltando modelos que transitam do erudito ao popular, do central ao periférico, do canônico ao não canônico.

Palavras-chave: Arte; b) Literatura; c) Leitura; d) Literatura Infanto-juvenil; e) Monteiro Lobato.

\section{BEHIND THE PICAPAU AMARELO ODISSEY: THE POETICS OF A STORY COUNTER.}

\begin{abstract}
Considering the hypothesis that it is possible to perceive the expression of a particular aesthetic thought in Monteiro Lobato's (1882-1948) texts, this research aims at tracing distinguished statements on art, literature, reading and child literature in his production during over forty years of intense intellectual militancy (1903 - 1948). Accordingly, the survey, selection and analysis of thirty-five literary publications - covering what is conventionally designated as "general literature" and "child literature" - as well as five journalistic essays selections and three volumes of letters published by Brasiliense is intended to be conducted. On the other hand, the registers left by Lobato, showing various contradictions, aggregate the membership to a diversity of philosophical threads, insist in the subversion of the foreign patterns and stress a productive dialogue with various cultural systems, elevating models that range from the scholarly to the popular, from the central to the peripheral, from the canonical to the non-canonical.
\end{abstract}

Keywords: Art; b) Literature; c) Reading; d) Child literature; d) Monteiro Lobato.

\footnotetext{
${ }^{1}$ Este artigo é um recorte de minha tese de doutorado, intitulada Reinações na Jecatatuasia: aspectos estético-sociológicos da arte segundo Monteiro Lobato, direcionada ao delineamento da poética lobatiana inscrita em seus textos artísticos e jornalísticos. 


\section{INTRODUÇÃO}

Monteiro Lobato foi o primeiro intelectual brasileiro que dedicou sólida parte de suas publicações à criança. Autor altamente versátil, edificou uma obra polêmica, heterogênea e abrangente, que se estende da ficção à ensaística. Na notável condição de personalidade multifacetada, atuou ao longo das décadas em distintas atividades. Como jornalista, transitou pela imprensa lançando artigos que contemplavam uma significativa variedade de assuntos. Como interlocutor, nas periódicas correspondências mantidas com amigos e admiradores, preservou para a posteridade suas mais íntimas aspirações em relação ao país. Ocupando o posto de implacável escritor, fez da literatura sua tribuna, versando sobre questões políticas, sociais, econômicas e estéticas.

No que tange particularmente ao setor infanto-juvenil, Lobato rubricou produções de expressivo teor filosófico e intenso nível poético, intercalando contadores de histórias, leitores idealizados e uma vasta biblioteca povoada por personagens estilizados que, pouco a pouco, passaram a integrar o imaginário nacional. Ao mesmo tempo, acabou desencadeando nos meandros de sua narrativa um complexo processo labiríntico que conduzia o destinatário a um vasto repertório intertextual composto pelos contos clássicos europeus, bem como pelo cinema norte-americano, a mitologia greco-romana e o folclore local.

Considerando tal quadro, o presente estudo, centrado na pesquisa bibliográfica e na análise documental, ocupa-se em rastrear, mapear e problematizar a complexa rede de reflexões em torno do conceito de literatura infanto-juvenil inscrito no pensamento estético de José Bento Monteiro Lobato.

\section{METODOLOGIA}

Segundo Marconi e Lakatos (1983), a metodologia compreende a organização do trabalho científico fundamentada em um viés epistemológico. Frente a isso, as autoras explicitam duas formas intrínsecas de ordenamento metodológico: o técnico e o teórico-conceptual. Reconhecendo a metodologia como uma prática inserida em uma corrente de pensamento acumulado, Marconi e Lakatos enfatizam a natureza teórica de toda produção acadêmica, afirmando que a metodologia deve implicar, além de uma organização meramente formal do trabalho, ou seja, um processo de agrupamento de passos para se chegar a um fim, também um prévio conceito direcionado ao objeto perscrutado. Mediante esse quadro, para se desenvolver a pesquisa acerca da temática em questão, partimos da organização conceptual calcada nas vertentes teóricas que abordam a escritura não apenas em sua imanência, mas também em sua dimensão pragmática, examinando-a, prioritariamente, em sua horizontalidade e em sua verticalidade. Nessa linha, recorremos aos estudos de Eco (1964, 1979, 1980, 1984, 1985 e 1991), Jauss (1967), Iser (1972) e Stierle (1976), bem como aos seus principais comentadores, cabendo aqui citar Lima (1979), Eagleton (1985), Zilberman (1989) e Compagnon (2003) .

\section{RESULTADOS}

A concepção de literatura infanto-juvenil que sustenta o projeto de Monteiro Lobato compreende um desdobramento de suas ideias gerais sobre literatura. Em linhas gerais, o ficcionista enaltece textos claros, concisos, revestidos de dinamismo, destituídos de digressões e capazes de instruir e, ao mesmo tempo, deleitar o interlocutor - o que, na verdade, refletia uma preocupação do autor com a formação dos filhos, tendo em vista que os livros que circulavam na época eram de âmbito monológico e estritamente utilitaristas. Monteiro Lobato viabilizou, mediante intertextos e interdiscursos, algumas adaptações do cinema, dos cartuns, dos clássicos da literatura europeia, do folclore nacional e da mitologia greco-romana para a vertente infantojuvenil. Nessa linha, assinala-se "O Irmão de Pinóquio" e "Gato Félix", ambos enfeixados em Reinações de Narizinho. Sublinha-se, paralelamente, Histórias do Mundo para Crianças (1933), 
Serões de Dona Benta (1937), Histórias de Tia Nastácia (1937), O Minotauro (1939) e Os Doze Trabalhos de Hércules (1944).

Nessa direção, vale ainda observar como o espaço sítio se revestia de absoluta função sígnica no conjunto de narrativas editadas pelo romancista. Segundo Lajolo e Zilberman (1984), o sítio não se definia apenas um cenário idílico onde a ação transcorria, mas representava a idealização lobatiana do mundo e da sociedade. Assim, está corporificado no local um projeto literário articulado a uma ampla aspiração política que envolve o Brasil, como o próprio autor assume na entrevista concedida a Mário da Silva Brito.

Lajolo e Zilberman negam que o espaço fictício do Picapau Amarelo deva ser interpretado somente como um retrato da sociedade rural brasileira. Alegam que consentir com essa ideia corresponderia a transferir uma atitude conservadora para o literato, já que o país começava a passar por um avançado processo de urbanização para o qual Lobato estava totalmente alerta. Assim, embora o texto permita outras possibilidades de leitura, o fragmento anterior atesta quanto ao anseio do autor em edificar um universo que assimilasse tudo o que sonhava com relação à pátria, à nação.

O sítio, nessa linha, torna-se portador de um caráter bastante agregador, destituído de qualquer preconceito, uma vez que se mantinha aberto a todos indistintamente e, em especial, às experiências mais modernas. Além disso, o local era governado por uma mulher, D. Benta, que sabia exercer a democracia, bem como o socialismo, e não se escandalizava com a tecnologia, embora renegasse as consequências desta por julgá-las nefastas.

Os personagens femininos, inclusive, ganham ênfase na narrativa em debate, cabendo aqui citar a figura de Emília. Para a boneca, o divórcio - inexistente no Brasil na época em que Reinações de Narizinho foi lançado - é apresentado como socialmente aceitável e até necessário (KLINKE, 1999). Além disso, o nome Emília, reportando ao título da obra máxima de Rousseau, permite detectar a adesão do autor aos princípios do filósofo francês no que tange à hipervalorização da infância. Na condição de alter-ego de Lobato e grande heroína da série, acaba sempre liderando as crianças nas viagens de exploração por dimensões desconhecidas e lugares ermos. Em outro polo, o nome da garota do nariz arrebitado igualmente insinua um sentido obtuso: Lúcia, aquela que é revestida de luz, instaura uma nova fase na história da literatura infanto-juvenil brasileira, até então marcada pela tradição do acervo literário europeu e pela veiculação de textos ufanistas. Ao "incentivar" as personagens dos contos tradicionais a fugirem dos livros que circulavam naquele período, possibilitando com que povoassem as terras de D. Benta, Narizinho viabiliza a construção de uma nova proposta literária frente ao tétrico quadro de sua época. A partir daquele feito, o Brasil poderia finalmente contar com narrativas dinâmicas, imprevisíveis, autênticas e, sobretudo, inéditas, destinadas a leitores em formação.

\section{DISCUSSÃO}

Entre os seis personagens predominantes na obra - D. Benta, Tia Nastácia, Pedrinho, Narizinho, Emília e Visconde - dois constituem figuras adultas e dois representam crianças. Esses personagens, inclusive, são caracterizados por distintas relações sociais que permitem inseri-los no quadro da típica sociedade brasileira do século XIX: uma avó, proprietária do Sítio, seus netos e uma velha empregada. No entanto, sobressaem algumas particularidades dessa família: a ausência de pai e mãe, agentes associados ao processo e socialização da criança, e o fato de, em um cenário tão patriarcal quanto o brasileiro do período, serem femininas as reconhecidas autoridades existentes nas terras do Picapau Amarelo.

A questão da representação das idades e dos papéis sociais adquire maior complexidade quando se adentra o caso de Emília e Visconde de Sabugosa, visto que são figuras circunscritas ao espaço do maravilhoso: uma boneca falante e um sábio sabugo de milho. Atendo-se especificamente à imagem de Emília, Vasconcellos (1982) afirma que esta desempenha uma 
função sui generis na produção lobatiana. Por um lado, não é uma criança e comporta várias características que a distanciam das "crianças propriamente ditas" da narrativa, Pedrinho e Narizinho. Por outro, é exatamente o fato de ser uma boneca que a destitui da obrigatoriedade de possuir bom comportamento. "Passa assim a representar exatamente os impulsos reprimidos das crianças, livres da influência educativa, o que a torna excelente alvo de identificação por parte dos leitores" (VASCONCELLOS, 1982, p.140) .

No geral, cumpre sublinhar que a concepção lobatiana de infância é bastante influenciada pelo clássico de J. Barrie, que é contemporâneo ao autor brasileiro, Peter Pan. (1911). Seguindo as trilhas do personagem escocês que almejava preservar-se na condição de criança - o que enfocava, exaltava e acentuava as particularidades de tal fase da vida - Lobato, em diferentes momentos de sua literatura, sublinha o encanto inerente à infância, contrapondo-o, de maneira drástica, ao marasmo peculiar à idade adulta. Por isso, seus personagens sentem a necessidade de se exibirem como crianças, preocupando-se com a lenta imposição dos anos de maturidade. É o que se revela em Reinações de Narizinho (1931) a partir do receio de Pedrinho em crescer, mesmo consciente de que isso era inelutável.

\section{CONCLUSÃO}

Dispensa-se um eloquente discurso para comprovar a relevância da produção de Monteiro Lobato no que tange à formação de um novo conceito de literatura infanto-juvenil no Brasil. A vasta fortuna crítica que se impôs após os anos 50, agregando artigos, resenhas, ensaios, dissertações, teses e biografias, basta para ilustrar a revolução conceptual que significou a circulação do Sítio do Picapau Amarelo no que diz respeito aos procedimentos adotados no ato de escrever para crianças.

Igualmente solidário a esses procedimentos, o ficcionista Jerônimo Monteiro edificou uma literatura bastante alternativa em sua época. As cartas compiladas nessa pesquisa atestam claramente como tal contista foi influenciado pelo intelectual no limiar de sua carreira. Assim, na mesma proporção que o citado escritor enveredou pela herança lobatiana, a proposta de Lobato, concomitantemente, pautava-se nas leituras de outros expoentes que o precediam, como Andersen, Barrie, Collodi, Carroll, Kipling, London e De Amicis. Demonstrava apreciar tais autores pelo fato de aderirem a um novo modelo nos modos de tessitura do texto literário, não mais concentrando a narrativa em ambientes palacianos ou reproduzindo a modelar estrutura dos contos de fadas. A opção por esse caminho, entretanto, não significa que o romancista desprezasse, de maneira radical, as construções de Charles Perrault ou dos alemães Jacob e Wilhelm Grimm. No ensaio "A Criança é a Humanidade de Amanhã", que faz parte do volume Conferências, Artigos e Crônicas (1948), ele se declara fascinado pela ficção Chapeuzinho Vermelho. Pronunciamento semelhante pode ser apurado em uma missiva enviada ao colega Rangel no ano de 1945, em que elogia a concisão peculiar ao estilo da apontada narrativa.

\section{REFERÊNCIA}

BIGNOTTO, C.C. Duas Leituras da Infância Segundo Monteiro Lobato. In: GOUVÊA, M..C.; LOPES, E. M. Lendo e Escrevendo Lobato. Belo Horizonte: Ed. Autêntica, 1999.

COMPAGNON, A. O Demônio da Teoria: Literatura e Senso Comum. Tradução de C. P. B. Mourão. Belo Horizonte: UFMG, 2003.

EAGLETON, T. Teoria da Literatura: uma Introdução. Tradução de W. Dutra. São Paulo: Martins Fontes, 1985.

ECO, U. Apocalittici e Integrati. Milano: Tascabili Bompiani, 1964. 
. A Estrutura Ausente. Tradução de P. Carvalho. São Paulo: Perspectiva, 1971.

. Lector in Fábula: a Leitura do Texto Literário. Tradução de M. Brito. Lisboa: Editorial Presença, 1979.

- Tratado Geral de Semiótica. Tradução de A. P. Danesi e G. C. Souza. São Paulo: Perspectiva, 1980.

. O Nome da Rosa. Tradução de A. F. Bernardini e H. F. de Andrade. Rio de Janeiro: O Globo, 1984.

. Pós-escrito ao Nome da Rosa. Tradução de L. Z. Antunes e A. Lorenzini. Rio de Janeiro: Nova Fronteira, 1985.

Ática, 1991.

Semiótica e Filosofia da Linguagem. Tradução de M. R. Fábio e J. L. Fiorin. São Paulo:

ISER, W. A. A Interação do Texto com o Leitor. LIMA, L. C. A Literatura e o Leitor: Textos de Estética da Recepção. Rio de Janeiro: Paz e Terra, 1979.

JAUSS, H. R. A História da Literatura como provocação à Teoria Literária. Tradução de S. Teradolli. São Paulo: Ática, 1994.

KLINKE, K. Um Faz-de-Conta das Meninas de Lobato. In: GOUVÊA, M. C.; LOPES, E. M. Lendo e Escrevendo Lobato. Belo Horizonte: Ed. Autêntica, 1999.

LAJOLO, M.\& ZILBERMAN, R. Literatura Infantil Brasileira: História e Histórias. São Paulo: Ática, 1984.

LIMA, L. C. A literatura e o Leitor: Textos de Estética de Recepção. São Paulo: Ática, 1979.

MARCONI, M. A; LAKATOS, E. M. Metodologia do Trabalho Científico. São Paulo: Atlas, 2001.

STIERLE, K. Que Significa a Recepção de Textos Ficcionais? In: LIMA, L. C. A Literatura e o Leitor: Textos de Estética da Recepção. Rio de Janeiro: Paz e terra, 1979.

VASCONCELLOS, Z. M. C. O Universo Mágico da Obra Infantil de Monteiro Lobato. São Paulo: Editora Traço, 1982.

ZILBERMAN, R. A Literatura Infantil na Escola. São Paulo: Global Editora, 1982.

. Atualidade de Monteiro Lobato: Uma Revisão Crítica. Porto Alegre: Ed. Mercado Aberto, 1983.

. Estética da Recepção e História da Literatura. São Paulo: Ática, 1989. 